\title{
Historia versus realidad: «El patriarcado historiado» y la simbología de la serpiente antes y después del cristianismo ${ }^{1}$
}

History versus reality: The "historiated Patriarchy" and the symbols of the snake before and after Christianity

María de Lourdes Girón Anguiozar

Escuela Superior de Igualdad Real

H.C.C.

lou.gir.ang@gmail.com

\section{Resumen}

En este artículo se cuestiona la formación de la historia como ciencia verídica. El problema con el que nos encontramos es la invención de una epistemología que ha establecido los principios, los fundamentos y los métodos del supuesto conocimiento humano para crear el patriarcado. La Historia ha sido creada por hombre y para el hombre, además, de estructurar la imagen de la mujer como algo secundario y servicial.

Palabras clave: Patriarcado historiado, Deconstrucción, Simbología, Serpiente y diosa madre.

\begin{abstract}
This article questions the formation of history as true science. The problem we encounter is the invention of an epistemology that has established the principles, foundations and methods of supposed human knowledge to create patriarchy. History has been created by man and for man, in addition, to structure the image of women as secondary and helpful.
\end{abstract}

Keywords: Historiated Patriarchy, Deconstruction, Symbols, Snake and mother Goddess.

\section{Introducción}

¿Qué es la realidad? ¿Lo que estudiamos en los libros, leemos en las publicaciones, etc. se corresponde siempre con los hechos acontecidos? La historia siempre la escriben los que vencen y los que están en la posición de poder ejercerla para ilustrar solo aquello que

${ }^{1}$ Recibido 01/02/2021 Evaluado: 02/03/2021 Aceptado: 19/04/2021 
consideran idóneo en su sistema. Pero la historia ausente también educa, es nuestra responsabilidad desgranar los entresijos de esta supuesta realidad histórica actual y separar lo realmente histórico de lo historiado.

Con este trabajo pretendemos presentar una propuesta para deconstruir la creación de la historia inventada por el prisma patriarcal para establecer y reorganizar ese "ADN" de la memoria humana como la entendemos actualmente. La mujer no ha sido tenida en cuenta para la formación de esta, cuando si debió existir alguna vez un primer humano, debió ser mujer, ya que es la única capaz de reproducir, lo que en la Comunidad Científica conocemos y llamamos como la "Eva Negra".

La temática va a girar en torno a la comparativa simbólica de la serpiente en diferentes culturas, su origen, evolución desde el Paleolítico Superior hasta época del cristianismo primitivo, con el fin de comprender mejor la doble naturaleza mitológica de este animal: de un lado, dañino y peligroso, de otro, beneficioso y protector. Al mismo tiempo, analizaremos como las diversas sociedades del Mediterráneo han relacionado la serpiente a la mujer, y cómo esta ha marcado la designación de ciertas prácticas y oficios femeninos en una de las principales religiones monoteístas en Occidente: el cristianismo. Ideas que llegan a la actualidad como si fueran instrucciones genéticas de una transmisión heredada de origen divino incuestionable.

Un desequilibrio histórico que deja la huérfana. Varias preguntas surgen y que intentaremos dar respuesta en las siguientes líneas, ¿por qué imponer una historia de la masculinidad sobre la femenina? ¿Qué hay detrás de ese gran esfuerzo por parte del sistema para esconder la brillantez y la inteligencia de la mujer en todas las épocas que nos han precedido hasta lo que conocemos como época moderna? Se habla de una prehistoria del patriarcado (Segato, 2003; 2016), yo considero que es a partir de los siglos XVII-XVIII cuando se comienza a crear el prototipo del patrón patriarcal prehistórico para amparar y prolongar la agonía de una historia forzada que tiene sus días contados.

Culpar a la Prehistoria del origen patriarcal es fácil, pero ¿quién ha escrito y organizado la Historia de la Humanidad que hoy conocemos? ¿Qué nos han querido transmitir? ¿Cuál ha sido la función de este "patriarcado historiado"? Y algo que consideramos más importante, ¿entorno a qué se organiza y cómo se data esta? Hay dos ítems de periodizaciones que han marcado la cronología de la Historia occidental: por un lado, el Génesis, el primer intento de ordenarla; y, por otro, la tesis hegeliana que sienta las bases de lo que hoy conocemos como las épocas clásica, media y moderna, en estrecha relación con el cristianismo y la cultura filosófica griega (Hegel, 1991). Ambas bajo un esquema androcéntrico, eurocéntrico, patriarcal y patrimonial (entendido como la herencia del linaje de lo masculino), famosa por el antes o después de Cristo.

Aunque esta reflexión es parte del problema, solo ejemplificamos un punto para indagar en la significación del mismo y en la creación de la simbología. El inconveniente siempre ha estado ahí pero no así sus formas de abrir nuevos caminos para deconstruir la Historia en clave de igualdad. Componer un modelo para despatriarcalizar nuestros orígenes puede suponer desestabilizar uno de los edificios de poder del sistema patriarcal que basa gran parte de su existencia en la genealogía histórica, profiriendo una supuesta autenticidad. 
Identificar el patrón del patriarcado historiado debe ser el punto de partida para reconocer el "hilo conductor", su contexto, desarrollo y consumación actual. En los ejemplos que vienen a continuación profundizaremos en la deconstrucción del poder de la mujer por parte de la tradición judeo-cristiana en un párrafo del Génesis y la simbología de la serpiente.

\section{Antecedentes y justificación}

La violencia es un tipo de interacción entre varios sujetos en la que se intenta imponer una conducta o situación, de forma deliberada, para el sometimiento a una persona o a una colectividad. El patriarcado historiado [el primer sujeto] ha sometido a lo largo de un período de tiempo a la sociedad [el segundo sujeto] en la que ha inventado hechos ficticios y/o ha ocultado acontecimientos reales, creando vínculos simbólicos para normalizar una epistemología patriarcal inexistente. La creación de "dichas conductas vinculadas con los simbólico" son eslabones de una cadena de opresión que nos ha hecho prisioneras y prisioneros de un sistema con un patrón cultural de "profunda violencia histórica" que ha supuesto el enaltecimiento de una supuesta superioridad "natural" del hombre sobre la mujer. Esta ideología patriarcal ha elaborado un patrón para vaciar de realidades y de dignidad a la Prehistoria e Historia de la Humanidad, porque sin darnos cuenta la sociedad va aceptando como normal una epistemología que no se cuestiona pero que ha servido para modelar la sociedad en la que estamos.

Esta organización social primitiva machista que predomina en la actualidad no es sino el resultado de una serie de "contextos" falseados desde las instituciones políticas, académicas y religiosas para regularizar roles históricos "preestablecidos" y reglamentar neuronalmente la consciencia humana en su beneficio. Pero estas realidades vienen además alimentadas de forma transversal por todo tipo de procedimientos (literatura, cine, etc.) con el que, por un lado, mantener la quimera de las historias gloriosas de nuestros antepasados masculinos y, por otro lado, desprestigiar contextos que en la actualidad no están en consonancia a la visión eurocéntrica. Sirva como ejemplo, el caso del origen de la Humanidad vista desde el cine, en 2001, el director Stanley Kubrick, en su película Una Odisea en el Espacio, crea el concepto del australopithecus hostil -primera escena entre dos grupos de primates rivales- (cuya base está en El Centinela de Arthur Clarke) (Castellanos, 2008). Con ello, se crea una lectura de fácil entrada en la cosmovisión neurológica humana, creando pensamientos inconscientes que nos conducen a elegir entre opciones "dirigidas" de un comportamiento hacia un tipo de experiencias actuales para reprogramar la mente subconsciente. El mensaje a difundir con esta película es bastante claro: el hombre que procede de África es violento y territorial, incluso, otra idea subyacente que se corresponde con el nacimiento de la humanidad africana (salvaje y territorial) pero que se "sociabiliza" con la entrada en el Occidente Mediterráneo, para, de nuevo, argumentar el eurocentrismo como única cuna de civilización "educadora".

Diversos estudios en el área de la Antropología, Arqueología y de la Historia apuntan al problema de atribuir roles previamente establecidos para redirigir la forma con la que verla, pero desde perspectivas estrictamente sociales, dejando fuera un tema tan profundo del porqué, eje central de este estudio. Investigadoras como Ruth Falcó Martí ha realizado un extenso análisis de aquellas investigaciones centradas solo en el hombre a lo largo de la historia así como, los roles preestablecidos por sexos sin fundamento (Falcó, 2003). Del mismo modo, son muchas las publicaciones que van al hilo de reflexionar sobre los 
cometidos históricos específicos para diferenciar lo biológico de lo cultural (Pateman, 1995; Puleo, 2013; Scott); los estudios desde diferentes tendencias historiográficas tales como la perspectiva marxista, postestructuralista; o, historiografías actuales analizando las contribuciones de las mujeres a lo largo de la Historia (Falcó, 2003). Los estudios de Gerda Lerder sobre La Creación del Patriarcado propone que para acabar con este sistema se debe invertir el proceso histórico que lo creó (Lerder, 1990).

El sistema patriarcal es el resultado de una arquitectura sepulcral de historias y realidades ideadas y fraguadas en las más altas esferas de dominio con el fin de someter la mente humana de forma casi inconsciente. En torno a ella, se han ido hilando y edificando edificios de poder generadoras de voces "adultas" -académicas, institucionales, etc.- y oficiales donde argumentar las perspectivas del género masculino historicista marcado por un supuesto determinismo biológico. No somos conscientes que la historia como ciencia escrita apenas se cuestiona pero, sin embargo, es la que sostiene toda nuestra realidad.

El sistema patriarcal es el resultado de una arquitectura sepulcral de historias y realidades ideadas y fraguadas en las más altas esferas de dominio con el fin de someter la mente humana de forma casi inconsciente. En torno a ella, se han ido hilando y edificando edificios de poder generadoras de voces "adultas" -académicas, institucionales, etc.- y oficiales donde argumentar las perspectivas del género masculino historicista marcado por un supuesto determinismo biológico. No somos conscientes que la historia como ciencia escrita apenas se cuestiona pero, sin embargo, es la que sostiene toda nuestra realidad.

Deshacer analíticamente los elementos que constituyen la estructura conceptual del patriarcado; así como, revisar, reescribir y verificar cada uno de los ítems históricos que sostienen a este sistema, debería ser una de las bases para identificar cómo actúa éste en el desarrollo de sus estructuras de pensamiento y su simbología. Además, con ello analizar los preceptos que se emplean para justificar los datos científicos.

El resultado actual es, en gran parte, una historia creada para someter la inteligencia y brillantez de la mujer a partir de pequeñas realidades disfrazadas de voces "adultas" masculinas que en sus ansias de dominación, a la vez que, ignorancia consideran que educar la eterna "niñez" femenina es la solución para mantener su régimen misógino, porque para el patriarcado aún seguimos siendo "niñas" a las que adiestrar y llevar por "el buen camino".

\section{Metodología y objetivos}

Crear un método para deconstruir los fundamentos, los principios y el sistema en el que se basa el patriarcado a lo largo de la historia no es fácil, es por ello, que es necesario miradas y voces desde diversas culturas, clases, géneros, etc., así como, la transversalidad en todos los aspectos (historia, antropología, periodismo, psicología, derecho, etc.) para construir un espacio de transformación. El giro epistémico es fundamental para afrontar y cambiar los obsoletos paradigmas coloniales del poder y del saber, y, con ello, modificar la hegemonía geopolítica del conocimiento en la construcción de un mundo más equitativo; sin duda, una transformación social, cultural, histórica y colonial necesaria para avanzar como sociedad desde la igualdad (Walsh, 2004). 
Así se ha creado la Historia que hoy conocemos, sin la mirada incómoda o "del/de la historiador/a inoportuno/a", con el peligro de una sola versión y la creación de estereotipos y prejuicios que no reflejan la realidad ni antigua ni actual y, por ende, son los causantes de las exclusiones, las discriminaciones y las marginaciones de ciertos grupos sociales. Un formato subrogado por el patriarcado, en la que se ha sustituido la historia real por otra, en gran parte, inventada, de forma periódica y obligada.

Es un deber de todas y todos deconstruir la creación del "patriarcado historiado" por el prisma misógino para establecer y reorganizar ese "ADN" de la memoria humana como se entiende actualmente. Equilibrar y reescribir la historia en Igualdad para acercar a la cultura academicista y oficial a explorar otras realidades históricas que forman parte de nuestras vidas y nuestra cultura.

El objetivo principal de esta investigación es iniciar la deconstrucción de las "historias patriarcales" que han marcado el devenir del contexto en el que vivimos, realidades creadas desde un prisma patriarcal donde los agentes socios-culturales han recreado la epistemología que hoy conocemos como auténtica y real para el sometimiento de la sociedad, especialmente, de la femenina. E identificar el "hilo conductor" de los prejuicios y estereotipos actuales en su estrategia actual de acción, su desarrollo histórico para localizar su origen.

\section{Modelos de Investigación}

\section{La figura femenina en el cristianismo primitivo y la simbología de la serpiente}

Trataremos solo un fragmento del Génesis y desglosaremos de forma superficial, buscando los orígenes contextuales y desgranando en parte la metodología empleada para la implantación del culto.

Cuando la mujer es creada en la religión judeo-cristiana es la responsable de todos los pecados capitales y en las primeras líneas del Génesis ya nos adelanta por donde sufriremos (por el útero) y la sumisión al patriarca (hombre), pero la expresión más interesante está en la "enemistad entre linajes" y algunos conceptos en su contexto histórico: "Enemistad pondré entre ti y la mujer y entre tu linaje [el de la serpiente] y su linaje: él te pisará la cabeza mientras acechas tú su calcañar". A la mujer dijo: "Tantas haré tus fatigas cuantos sean tus embarazos: con dolor parirás los hijos" (Gen. 3, 15-16).

Para reorientar la historia, al menos del patriarcado cristiano, nos tenemos que retrotraer supuestamente al 450 a.n.e. aproximadamente (aunque esta fecha solo es una referencia no corroborada científicamente en ningún momento y es posible que su creación sea mucho más moderna) para profundizar qué significado tiene el concepto "serpiente" y las funciones verbales "acechar" y "pisar". Acechar tiene la misma raíz šuf que el verbo "pisar", pero el primero viene del latín assectari > adsequi que significa "perseguir para atrapar", la persona que acecha es el que está en posición de vigilancia; mientras que, el término pisar proviene del latín vulgar pinsare, que significa "el que golpea el suelo con el pie". 
El otro símbolo a diseccionar es la serpiente, está en gran parte de todas las culturas precristianas; era venerada como símbolo de poder, sabiduría, fertilidad, magia, protección, etc. pero estudiaremos su origen vinculado a la mujer y la visión eurocéntrica durante la mitología grecorromana, donde se crea la historia del cristianismo. La serpiente como símbolo ha jugado un papel muy importante en las creencias de la cultura del Mediterráneo.

Las primeras evidencias las localizamos en la cueva de La Baume-Latrone (Sainte-Anastasie en Gard, Francia), fechada entre el 40.000 y 26.000 a.n.e., donde se documenta una de las primeras imágenes de una serpiente con colmillos y lengua bífida y la silueta de una mujer, interpretándose como la primera escena simbólica de la serpiente como mujer diosa. También durante el Magdalenense, en torno al 15.000 a.n.e. en la cueva de Lortet (Francia) se hallan objetos de huesos con relieves serpenteantes vinculados posiblemente a ritos estacionales de la primavera. Para algunos autores su culto podría estar en un origen biológico de superioridad con otro animales, incluido al ser humano (Duchateau, 1969) y para otros podríamos estar ya ante un símbolo sanador en el Paleolítico Superior (Clark, 1980).

Durante el Neolítico esta iconografía se mantiene, destacaremos algunas documentadas en el Mediterráneo, como las recreaciones de cabezas de serpientes en recipientes cerámicos de los yacimientos de Dimini, al norte de Atenas (5500-4500 a. C.); o, en grabados sobre piedra datados en torno al 6500-5000 a.d.n, en Tende (sur de Francia) y en Hacilar (Anatolia); y en torno al 4500-4000 a.d.n. en Beletinci (Yugoslavia) y en Munhata (Palestina) (Gimbutas, 1974).

Antes de ser un atributo en el antropomorfismo de la religión helénica formaba parte de las divinidades de la religión primitiva naturalista, íntimamente involucrada en la adoración de árboles, manantiales y lugares consagrados. Aunque su vinculación con el árbol y la manzana y posterior transformación en parte del pecado capital por la tradición judeo-cristiana será una investigación que trataremos en otra ocasión, solo indicar que procede del mito del Jardín de las Hespérides, donde en él se encontraba la serpiente protectora enroscada en el manzano con sus frutos dorados - de oro- que otorgaban la inmortalidad descritas entre otros muchos autores por Hesíodo en sus Teogonías, Esquilo en Prometeo liberado u Ovidio en sus Metamorfosis. Analizar estas fuentes leyendo entre líneas y los restos arqueológicos nos dará una visión hasta el momento no revelada-consciente o inconscientemente-por la Comunidad Científica.

La cultura prehelénica es heredera de todos estos ritos y parecen continuar el linaje matriarcal evidenciado en culturas anteriores, vinculándolo a la religión (Castleden, 1993; Goodison y Morris, 1998). En Creta, entre el 2000 y el 1400 a.n.e., se han localizado un gran número de ofrendas entre las que destacan las figurillas consideradas como "Diosas de las Serpientes", esta deidad viene representada con dos serpientes en ambas manos alzadas en señal de victoria o enredadas en su cuerpo, entre otras representaciones. El culto a la serpiente fue considerado tan importante que incluso se representa en las monedas en la que se observa a la Gran Diosa sentada debajo de un árbol acariciando la cabeza de una serpiente (Willetts, 1995; Ogden, 2013). Resulta cuanto menos curioso que siendo una religión no antropomórfica sí existieran representaciones femeninas como tal, como la mencionada anteriormente, o en sus advocaciones de "Gran Diosa Madre o Gran Dama del Laberinto". Estas se consideraban símbolos de la fertilidad y posiblemente herederas de las figuras-diosas 
femeninas neolíticas (Willets, 1958), así como de la dualidad y la integración del opuesto (Willetts, 1995). Un claro ejemplo podría ser la "diosa serpiente" documentada en Kato Chorio (Creta), datada entre 6500-3500 a. C., en la que representa a una mujer sedente con el cuerpo hasta la cintura de una serpiente y el resto de una mujer (Charlesworth, 2010).

Sea como fuere lo trascendente es como siempre se vincula la serpiente a la mujer desde épocas prehistóricas hasta la clásica arcaica y esta es una de las características que nos debería hacer reflexionar sobre su relación directa considerada como un símbolo de la feminidad (serpiente=mujer). En los inicios de la cultura griega arcaica la serpiente por su ritmo progresivo, su gusto por la soledad, su costumbre a residir en las oquedades de la roca, en profundas grietas, la sociedad la dotó de poderes secretos que se ocultan en el corazón de la tierra.

$\mathrm{Su}$ transcendencia simbólica se centra a partir del siglo $\mathrm{V}$ a.n.e en la que las deidades personifican las cualidades secretas y misteriosas de la tierra atribuidas a la serpiente. El papel pacífico y beneficioso de la serpiente está marcado en las representaciones del dios sanador por excelencia, Asclepio y su hija Hygia, símbolo de las divinidades y de la ciencia médica en época griega. Durante la época romana sus representaciones son cuantiosas, incluso llegando a representarse en uno de los frescos de Pompeya en procesión como símbolo de los genios tutelares de las personas y el hogar (DARG, voz draco); del mismo modo es documentada, en cuantiosas ocasiones, en las intersecciones de las calles o en los lares de las casas como símbolos de protección (Ranieri, 2004). En algunas partes del imperio romano adquiere incluso la cualidad de "protectora de la virginidad" (Eliano, Nat. Anim., XI, 16).

Retornando a la cultura griega, la serpiente se asociaba (además de las cualidades dichas anteriormente) en su mitología a la mujer por su naturaleza cíclica; a la medicina por su facultad de "resucitar" al mudar la piel; incluso, de suponer la integración de los opuestos (algo totalmente en contra al dictamen del sistema patriarcal).

La imagen más conocida del dios Asclepios (dios griego de la medicina) es el caduceo (vara) en la que se entrelazan dos serpientes, esta imagen simboliza el equilibrio (dualidad cretense procedente de la Diosa Madre), la ecuanimidad, la unión y la regeneración. Las características principales que nos interesan son aquellas que provienen de la vinculación de este dios con las figuras femeninas familiares que también practicaban esta profesión: su mujer, Epíone, calmaba el dolor; y sus hijas, Hygia y Panacea, eran los símbolos de la prevención y del tratamiento, respectivamente; y, una tercera, que respondía a una semidiosa de la curación. Los símbolos de estas tres mujeres se pueden resumir en:

- Hygia fue diosa de la curación, la limpieza y la sanidad (posteriormente, también de la luna). Este epíteto lo obtiene a partir del siglo V a.d.n. (antes lo tenía la diosa Atenea). Pero lo que más sorprende son los atributos de esta diosa, un cáliz/copa y una serpiente enroscada en ella, también se le representaba de pie con una serpiente. La copa era considerada como el recipiente simbólico que contenía la vida; relacionado con el contenedor del medicamento, a su vez, símbolo femenino, por lo cual la mujer era la única que podía portarlo -contenerlo- dentro de sí. 
- Panacea, diosa que curaba todos los males con sus hierbas y ungüentos. Y aunque hay otra hermana, Yaso (diosa menor de la curación), solo Panacea e Hygia eran las que a través de rituales daban sus alimentos a las serpientes sagradas (hembras).

El dios Esculapio (asimilación del dios griego) era uno de los dioses del panteón romano más venerados, los procesos de aculturación religiosa siguen unos patrones muy bien definidos, trasmutar la simbología entre dioses (esa asimilación/aculturación/hibridismo religioso que se ha producido a lo largo de toda la Humanidad), a excepción de la simbología de la serpiente, que era identificada con la mujer.

Su asimilación, además de los edictos promulgados por Constantino I y Teodosio para establecer el cristianismo como religión oficial, comenzó por compartir espacio de culto con el dios Esculapio, prueba de ello son los restos arqueológicos documentados durante el inicio del cristianismo primitivo (siglos IV d.n.e.) en algunos templos de Roma dedicados al dios romano Esculapio que "usurpa" el dios cristiano. El modus operandi para trasmutar creencias religiosas se basa en crear un vínculo que relacione un dios venerado y respetado anteriormente para emparentarlo con uno nuevo. Del mismo modo, se asimilaba los atributos del dios anterior -Esculapio- al impuesto, el primero tenía barba y el cayado (símbolo de Asclepio/Esculapio), la nueva religión -cristianismo- lo asimila con los pastores de almas y, el báculo, en la actualidad como uno de los objetos más importantes de la liturgia del cristianismo.

Otros episodios siguieron para invertir valores con los que ir adoctrinando la sumisión de la mujer ante la sociedad masculina, de forma prácticamente inconsciente: el primero, dios convierte el bastón en serpiente ante la zarza ardiendo (Evang. 4: 2-4) -muy vinculado a la quema de brujas, por otro lado-; el segundo, en Egipto, cuando Aarón lanza el bastón al suelo, y este se convierte en serpiente devorando las de los magos de Faraón (Evang. 7: 10-3). Poco a poco, trasmutaron el concepto de la serpiente en mal; mientras el cáliz (vida eterna) y el bastón (golpeo y dirección de fieles, pastor-rebaño-adoctrinamiento) se lo apropian; asimilándolo para sus propósitos. Con ello, paulatinamente se hace desaparecer la figura de Esculapio y de Hygia (ya en época tardorromana y, sobre todo, de la mujer diosa) y cambiarla.

Uno de los poderes que sí se apoderaron y es estandarte del cristianismo es el de la resurrección, poder atribuido en la mitología grecorromana a Asclepio-Esculapio, capaz de devolver la vida a los muertos. Pero es una cualidad que posiblemente adquiere a través de la Diosa Madre del Paleolítico-Neolítico-Minoica.

La alteración perniciosa se cumple con la reivindicación del cristianismo en el Génesis, de no proseguir con la simbología gentil y compañera de los dioses, creando un poder perverso del reptil, donde esta es aniquilada bajo los pies de Adán. El cristianismo solo quiere transmitir una sola idea; la facultad corrompedora de la serpiente, o sea, de la mujer. Para ello se puso todo el empeño, llegando a la obstinación para aniquilar su simbología, incluso Constantino II, acuña una moneda donde aparece sobre su caballo pisando la serpiente con la inscripción debellator hostium, cuyo significado es "pisando al enemigo", como contrario de la raza humana, al menos, de la cristiana, proyectando una de las imágenes más prolíficas de san Jorge y del arcángel san Miguel en dicha religión. 
La metamorfosis simbólica de la serpiente hembra (sin la que no se podría engendrar linaje) y del enfrentamiento con la mujer en la cultura judeo-cristiana tiene como objetivo desafiar la inteligencia femenina entre nosotras. A su vez, la acción masculina de "pisar" se vería como un mandato divino impuesto para el control en caso de intentar recuperar los derechos ya obtenidos, como sucede en la actualidad; en tanto en cuanto, cuando la mujer pase a la acción, sus aspiraciones de igualdad serán "pisoteadas" por el sistema patriarcal, ejemplificado en un hombre blanco y vengativo, para encaminarnos de nuevo a la sumisión y obediencia.

No existe ninguna intención por parte del cristianismo del siglo IV d.n.e por conectar la simbología benéfica de la que gozaba la serpiente en la antigüedad. Mis preguntas -retóricas, claro- son: ¿Por qué el cristianismo se empeñó y empeña en relacionar la serpiente con el pecado original, con el mal y, por consiguiente, con la mujer, cuando este animal gozaba de todo el respeto? ¿Querían, acaso, oscurecer el poder de la mujer heredado desde el Paleolítico Superior? La copa la utilizan como la consagración el vino en la última cena y, sobre todo "El que come mi carne y bebe mi sangre, tiene vida eterna" (Juan 6, 53). Su sangre se bebe en el cáliz (objeto de una diosa romana y mujer), el tema de la carne podría estar relacionado con los ungüentos pero es muy posible (a la espera de investigaciones más profundas) que esté en relación con los sacrificios que se realizaban en los altares y que están constatadísimos en miles de fuentes escritas y en la Arqueología (y que se servían en patena, cuyo símbolo está representado en relieve en el lateral de los altares pre-cristianos). La idea es simple, el cristianismo utiliza la copa/cáliz para contener "la vida eterna", pensamiento permeado en la sociedad romana. Solo tomaron los símbolos que ellos consideraron idóneos, la vara, el bastón (porque además es el que golpea y dirige) y el cáliz. Todo ello para ensalzar la posición masculina y eliminar poco a poco el significado benéfico de la serpiente y, con ello, el de la diosa mujer, un referente posiblemente para la sociedad romana femenina.

La manipulación por parte del cristianismo en la construcción de un origen genético de superioridad masculina sentó las bases simbólicas de la civilización occidental. La desvalorización simbólica de la serpiente en una religión oficial del Imperio Romano en el siglo IV d.n.e. significó una pérdida paulatina pero efectiva en el tiempo de poder y visibilización en la sociedad de la época. Entre los objetivos de esta relación metalingüística hay un mensaje entrelíneas de lectura alegórica: si la serpiente era el símbolo del conocimiento, sabiduría, equidad, etc. encarnado en una mujer, poner enemistad entre linajes femeninos crearía las circunstancias idóneas para justificar la presencia patriarcal bajo su dirección y mando.

Una vez analizada la metáfora de estas tres líneas del Génesis 3, 15-16, se podría realizar otra lectura:

"Si tú, mujer, te atreves a osar volver a tener contacto con la serpiente [es decir, con la igualdad, conocimiento, etc., o, incluso, con otra mujer], el hombre [sistema patriarcal] se encargará de pisarte, controlarte y quebrantar tu linaje."

La actualidad, en base a la historia de este pensamiento judeo-cristiano, es un constructo de una sociedad patriarcal en el que el concepto de género no fue integrado como elemento 
estratégico en la arquitectura social romana, supuso su exclusión en la creación de la simbología femenina y la devaluación de lo divino de la mujer.

\section{Conclusión y análisis de las estructuras patriarcales historiadas}

En este apartado intentaremos dar respuesta a las preguntas realizadas en el texto. Comenzábamos con una que define nuestra situación actual, ¿qué es la realidad? Un cúmulo de historias que no necesariamente se corresponden con la verdad histórica, hechos inventados para dotar de una identidad "real" a un sistema patriarcal ficticio en su origen.

La artimaña miserable de la dominación y del miedo para inventar la historia, transmutarla y desfigurarla desde sus raíces en la que han saqueado hasta la piel de la Humanidad en el sentido más literal que nos podamos imaginar en nombre de un dios blanco, misógino y eurocéntrico, pone de manifiesto las realidades que se pueden crear para el control de la sociedad. Los fundamentalismos todo lo van creando con el propósito de someter algo a sus intereses. Es por ello, que deconstruir los hechos para desmontar el "patriarcado historiado" y equilibrar la historia es necesario para descubrir al patriarca verdugo de esta humanidad femenina.

Desde diversos postulados feministas se habla de una "prehistoria del patriarcado" sin que se haya analizado realmente la figura de la mujer en ese habitad, volvemos a caer en la trampa del sistema que ha creado una serie de roles discriminatorios en la prehistoria e historia para sustentar el origen biológico del patriarcado. Es de vital importancia analizar la información actual a través del "hilo conductor" de las figuras femeninas contemporáneas o recientes para ver su transformación e identificar donde se produce la trasmutación simbólica del significado con el fin de someter a la mujer a los mandatos recalcitrantes masculinos, para llegar a los cimientos del patriarcado historiado y desmontarlo.

Un claro ejemplo es el tema tratado aquí, como a través de la imposición de una religión monoteísta, la presencia e importancia de la mujer, simbolizada con la serpiente desde el Paleolítico Superior, se destierra al ostracismo histórico.

La violencia contra la mujer no es solo física o psicológica sino también, cultural e histórica, cuando sepultas, ocultas, transformas y silencias la autenticidad y la legitimidad de una epistemología femenina con más de 25.000 años de antigüedad, eres cómplice del genocidio de la Humanidad que ha supuesto y supone ese "patriarcado historiado" como modelo de opresión a los valores básicos de los Derechos Humanos Universales y, al derecho de la mujer a ser persona, parte de la Historia y vertebrador de la misma.

Más allá de las barreras simbólicas y socioculturales del "patriarcado historiado", la inteligencia femenina de la Gran Diosa del Paleolítico hasta el Neolítico en su testimonio tangible matrilineal trasmitió su sabiduría y brillantez, dejó en herencia símbolos, conocimientos, competencias y aptitudes para ser recuperados en un futuro en caso de degeneración humana. Cualidades que se engendraron en el respeto a la naturaleza de la Diosa Madre Tierra y aun habiendo sido violada, maltratada y sometida, la fuente de vida siempre se vuelve a regenerar para pasarnos el testigo de la Dignidad Humana, hoy llamada, Igualdad. 


\section{Referencias}

Castellanos, V. (2009). "Stanley Kubrick, un evolucionista cinematográfico. Origen y término de la cultura en 2001, una odisea del espacio". En CIENCIA ergosum, Universidad Autónoma del Estado de México, Toluca, México, pp. 15 - 29.

Castleden, R. (1993). Minoans: Life in Bronze Age Crete. London: Ed. Routledge.

Charlesworth, J. H. (2010): The Good and Evil Serpent, How a Universal Symbol Became Christianized. London: Yale University Press.

Clark, G. (1980). Mesolithic prelude. The paleolithic-Neolithic transition in old world prehistory. Edimburgh: Ed. University Press Edimburgh.

Dart, R. (1925). Australopithecus africanus: The Man-Ap of South Africa. Revista Nature 115, 195-199.

Duchateau, L. (1969). Le culte du serpent: histoire, religions, mythes, legendes, folklore, recits de vogayes et commentaire. Bruxelles: Les Laboratoires Iatrea.

Eliano, C.. Historia de los animales. Madrid: Ediciones Akal (Trad. J. Vara Donado 1989).

Falcó, R. (2003). La arqueología del género: Espacios de Mujeres, mujeres con espacio. Alicante: Edición electrónica: www.espagrafic.com

Gimbutas, M. (1974). Diosas y Dioses de la Vieja Europa (7000-3500 a.C.). Madrid: Ediciones Siruela.

Goodison, L. y Morris, C. (1998). Beyond the Great Mother: The Sacred World of the Minoans. En Goodison, L. y Morris, C. (eds.) Ancient Goddesses: The Myths and the Evidence (pp. 113-132). Madison: University of Wisconsin Press.

Hegel, G. W. F (1991). Filosofía de la historia. Barcelona: Ediciones Zeus (Trad., José María Quintana).

Lerder, G. (1990). La Creación del Patriarcado. Barcelona: Editorial Crítica.

Ogden, D. (2013). Drakon: Dragon Myth and Serpent Cult in the Greek and Roman Worlds. Oxford: Oxford University Press.

Pateman, C. (1995). El contrato Sexual. Barcelona: Eiciones Anthropos.

Puleo, A.H. (2013). El concepto de género como hermenéutica de la sospecha: de la biología a la filosofía moral y política. Revista Arbor, vol. 189. Recuperado de https://n9.cl/18ni [consultado 07/07/2019].

Ranieri, M. (2004). Pompeya: historia, vida y arte en la ciudad sepultada. Barcelona: Editorial Galaxia Gutemberg. 
Segato, R.L. (2003). Las estructuras elementales de la violencia. Ensayos sobre género entre la antropología, el psicoanálisis y los derechos humanos. Buenos Aires: Universidad Nacional de Quilmes Editorial.

Segato, R.L. (2016). La guerra contra las mujeres. Madrid: Editorial Traficantes de Sueños.

Walsh, C. (2004). Geopolíticas del conocimiento, interculturalidad y descolonialización. Boletín ICCI-ARY Rimay, Año 6, No. 60.

Willetts, R. F. (1958). Cretan Eileithyia. Revista The Classical Quarterly 8 (3-4), 221-223.

Willetts, R.F. (1995). The Civilization of Ancien Crete. Nueva York: University of California Press Collection. 